\title{
Cervical Myelopathy Secondary to Ossification of the Posterior Longitudinal Ligament in a Caucasian Patient
}

\author{
Falah B. Maroun, Akira P. Makino, Tommy R.S. Tong, Philip G. Perkins, \\ Rudolph Arts, Jacob C. Jacob and R. Reddy
}

\begin{abstract}
Cervical myelopathy consequent on ossification of posterior longitudinal ligament (OPLL) is very rare in Caucasians. A 65-year-old Anglo-Saxon woman developed progressive gait disturbance, paresthesia in both legs and urinary urge incontinence. Radiological examination showed OPLL from fifth to seventh cervical vertebral level; the dense OPLL was graphically displayed by three-dimensional computerized tomography. Medial corpectomy, C5 to C7, and removal of OPLL, with subsequent fusion C4 to TI using a free fibula graft resulted in clinical improvement. Three dimensional computerized tomographic imaging is a valuable diagnostic procedure in OPLL.
\end{abstract}

RÉSUMÉ: Myélopathie cervicale secondaire à une ossification du ligament vertébral commun postérieur chez une caucasienne. La myélopathie cervicale dérivant d'une ossification du ligament vertébral commun postéieur (OLVP) est trés rare chez les Caucasiens. La malade d'origine anglosaxonne ágée de 65 ans, dévelope des troubles progressifs de la marche avec paresthésies des deux membres inférieurs et incontinence urinaire. L'examen radiologique

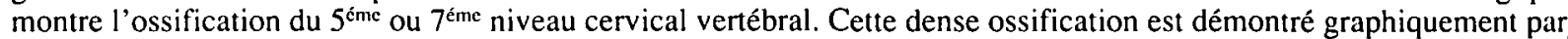
la tomodensimétrie tri-dimensionnelle. L'amélioration clinique est évidente après une vertébrectomie antérieure de C5 à $\mathrm{C} 7$ avec extirpation du ligament ossifié et greffe osseuse. La tomodensimétrie tri-dimensionnelle est une démarche diagnostique inportante dans l'O.L.V.P.

Can. J. Neurol. Sci. 1993; 20: 329-332

Ossification of the posterior longitudinal ligament (OPLL) is a common cause of cervical myelopathy in Japan but is very rare in Caucasians. ${ }^{1-3}$

\section{Case Report}

The patient is a 65-year-old housewife, of Anglo-Saxon descent who had lived and worked on a farm. In 1981 she developed low back pain and numbness in the gluteal region and thighs. A year later, paresthesia were experienced in the legs, including the dorsum of feet $(L>R)$, together with weakness in the left leg. There was progressive weakness of the left leg over the next eight years. In 1990 pins and needles sensation were noted in the left hand; as well as urgency of micturition.

Family history is non-contributory. Abnormality on clinical examination was confined to the central nervous system; speech, and cranial nerve functions were normal. Neck movements were unimpaired and pain free. On admission, she needed a cane to walk; gait was spastic. Relatively mild paresis of the left upper and lower limb muscles was detected. Hyperreflexia was clearly more marked in the left upper and lower limbs (compared with the right). She could not climb stairs without support. Upgoing left plantar response, left ankle clonus was elicited. Hypalgesia and dysesthesiae were noted below the level of the groin, and in the ulnar distribution of the left hand.

Laboratory investigations were normal, including urinary excretion of calcium and phosphate.

\section{Radiological Findings}

Lateral views of the cervical spine showed an irregular longitudinal retrovertebral opacity from C5 to C7 (Figure 1). Metrizamide myelogram showed total obstruction to flow of contrast at upper dorsal spine. CT scan demonstrated an intraspinal high density mass along the posterior aspect of the vertebral bodies from $\mathrm{C} 5$ to $\mathrm{C} 7$, which was compatible with OPLL (Figure 2). The spinal canal was markedly constricted at the sixth cervical level because of the OPLL. Three dimensional CT imaging (TCT - 900S Toshiba) clearly showed the ligamentous ossification extending from the posterior aspect of $\mathrm{C} 5$, down to the lower margin of $\mathrm{C} 7$, with the most prominent anteroposterior extension at $\mathrm{C} 6$ level (Figure 3).

\section{Operation}

Cervical traction using a Gardner-Wells skull tong (Codman, Boston, Mass.) was maintained during surgery. The anterior surface of vertebral bodies $\mathrm{C} 4$ to $\mathrm{T} 1$ was exposed through an oblique incision made along the anteromedial anterior margin of the left sternocleidomastoid muscle. Discectomy was carried

From the Division of Neurosurgery, Division of Orthopaedics (P.G.P.), Division of Neurology (R.A., J.C.J.), Department of Radiology (R.R.), General Hospital, Health Sciences Centre, St. John's, Newfoundland

Received December 21, 1992. Accepted in final form April 20, 1993

Reprint requests to: Falah B. Maroun, M.D., F.R.C.S.(C), Division of Neurosurgery, Faculty of Medicine, Memorial University of Newfoundland, Health Sciences Centre, 300 Prince Philip Drive, St. John's, Newfoundland, Canada A I B 3V6 


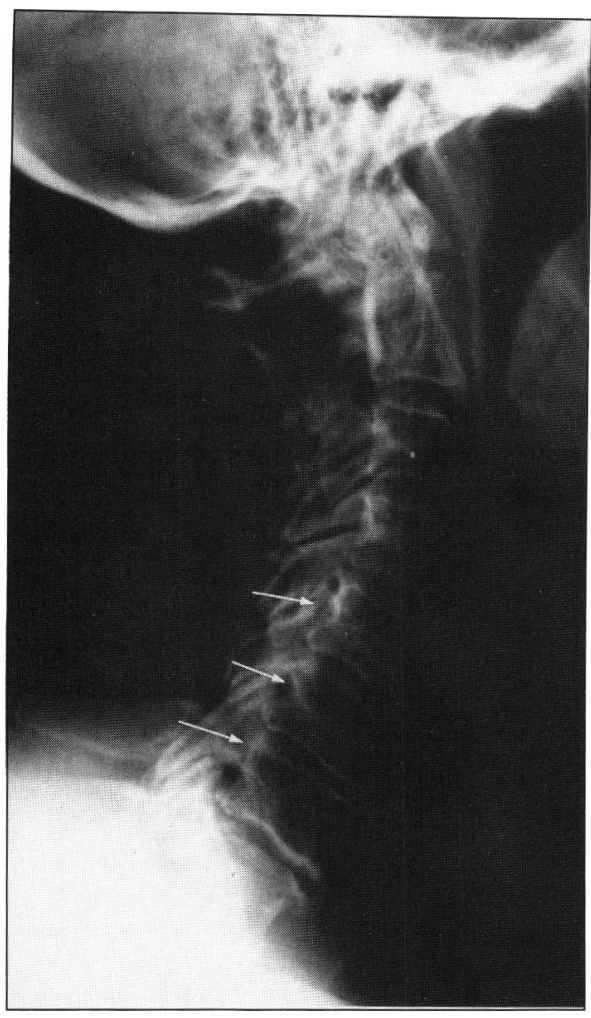

Figure I - Lateral Cervical X-ray. Irregular longitudinal retrovertebral opacity. out at $\mathrm{C} 4 / 5, \mathrm{C} 5 / 6, \mathrm{C} 6 / 7$ and $\mathrm{C} 7 / \mathrm{T} 1$ levels followed by medial corpectomy of the 5 th, $6 \mathrm{th}, 7 \mathrm{th}$ vertebral bodies. After drilling the cancellous bone of the vertebral body, the posterior cortical bone was noted to be partly fused with the ossified posterior longitudinal ligament. The ossified ligament was indenting the spinal cord. Since the ossification was firmly adherent to the dura in the thickest part, the mass of ossification was thinned out and left undetached from it. As soon as the main part of the ossification was removed the dura mater bulged upwards. Removal of the OPLL was done under magnification. A free Fibula graft was harvested from the left lower leg and was fashioned into appropriate contour. The cartilaginous surface of $\mathrm{C} 4$ and $\mathrm{T} 1$ was removed. A stainless steel screw was used to fix the graft on the vertebral body in each side (Figure 4).

The patient remained in traction for 4 days and was thereafter allowed to ambulate with a Halo Vest (Can-Med Surgical Supplies, Halifax, NS). Postoperatively, her gait improved and spasticity of the left leg decreased. Paresthesia in the left hand and both legs, as well as dysuria, resolved. Follow up 8 months post-operatively revealed slight spasticity and mild residual weakness of the left leg.

\section{Prevalence}

Various etiologies have been postulated for OPLL including degenerative disc disease, inflammation, trauma, chronic fluoride poisoning, and disordered calcium metabolism. ${ }^{3-9}$ High incidence among Japanese may suggest a hereditary predilection. However, none of the suggested etiologies has been proved to be definitively implicated in the pathogenesis of OPLL and this
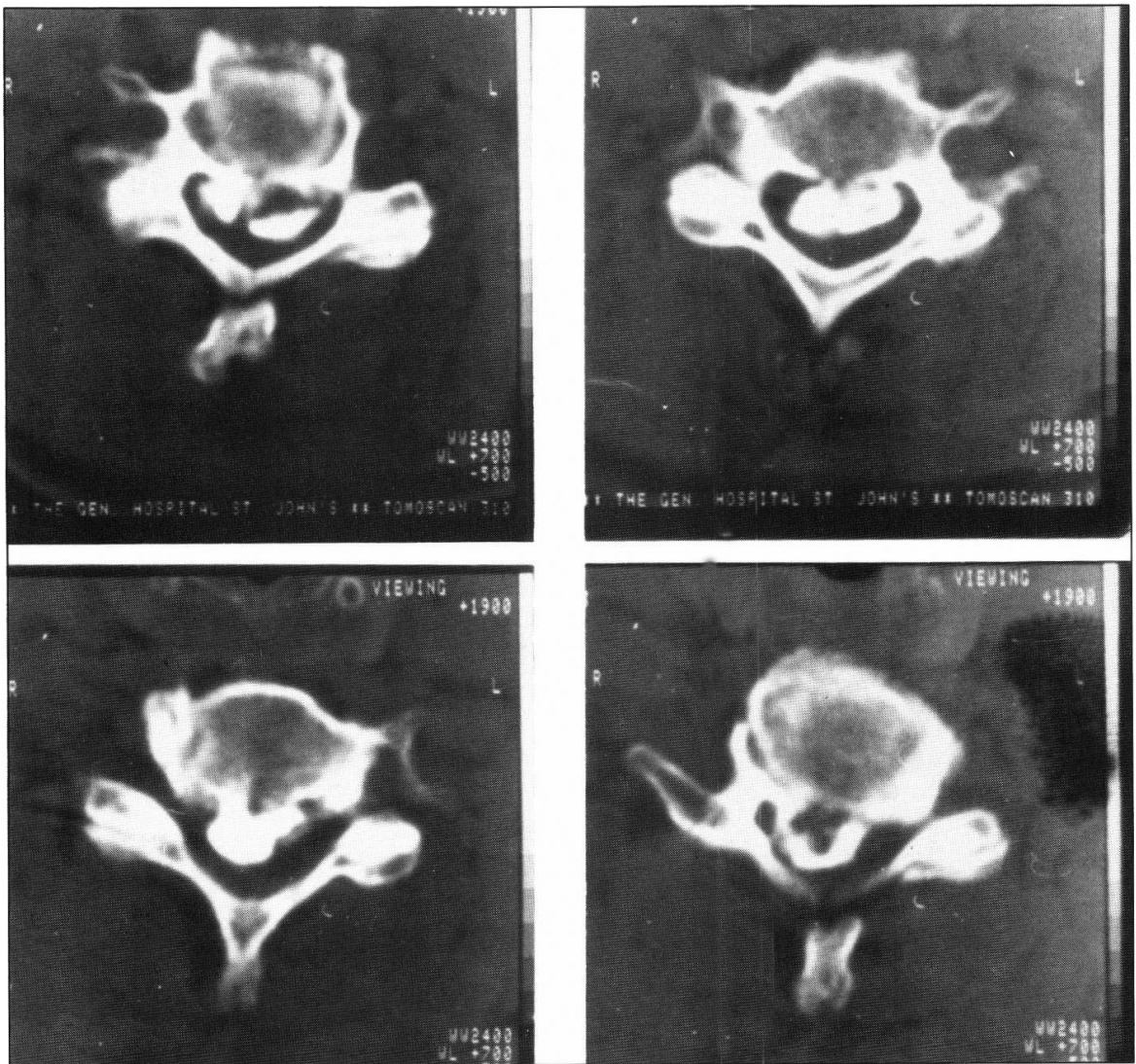

Figure $2-$ C.T. Scan. There is a huge high density mass attaching to the posterior aspect of the vertebral body. A bony density image shows the texture of the lesion is similar to the vertebral body. 
issue still remains to be elucidated. Yamauchi reported the prevalence of OPLL was $1.7 \%$ in Japan, Korea and Hong Kong, $0.2 \%$ in Mayo Clinic and $0.6 \%$ in Hawaii. ${ }^{10}$ In a review of plain cervical spine films, prevalence of OPLL among Japanese patients was $2.04 \%$ (143 of 6994), $0.95 \%$ in Koreans, $0.12 \%$ in North Americans and $0.10 \%$ in Germans. ${ }^{11}$ Lee $^{12}$ reviewed 5167 patients with cervical complaints and found 43 OPLL cases (0.8\%). Dong ${ }^{13}$ reported the incidence of OPLL as $0.5 \%$ (20 of 3694). Some clinical reports of cervical OPLL are common in Japan but very few in North America. ${ }^{2,14-18}$ This report seems to be the first one in Canada.

\section{Radiological Examination}

Longitudinal retrovertebral opacity is the most common finding of OPLL on plain cervical spine $x$-ray. This can be best diagnosed by CT scan. Saggital reconstruction aids estimation of the superoinferior extent of the mass. ${ }^{2}$ Metrizamide myelography and subsequent $\mathrm{CT}$ scan delineate the deformed cord well. ${ }^{2}$ MRI seems less effective than CT scan although it can also demonstrate cord compression. Three dimensional display of CT images is a relatively new technique to provide better information about the lesion and its structural characteristics. The basic process is essentially the same as two-dimensional reconstructive $\mathrm{CT}$ images but is the one-step advanced imaging method displaying sequential two-dimensional reconstruction views in overlaying fashion.

\section{Surgical Approach}

During the 1960's and 70's, posterior decompression was the procedure of choice. Nagashima reported 10 cases of OPLL treated by extensive decompressive laminectomy and multiple bilateral facetectomies, with or without foramen magnum decompression. ${ }^{19}$ However, complications though uncommon are known to occur following posterior decompressive laminectomy: postoperative losses of neural function due to manipulation of the spinal cord at surgery, production of further kyphotic deformity, secondary dislocation and formation of scar tissue leading to further posterior compression..$^{20}$ Postoperative spinal deformity with neurological symptoms can occur several years after operation. ${ }^{21}$ OPLL itself cannot be removed through the posterior approach and since nerve roots remain stretched

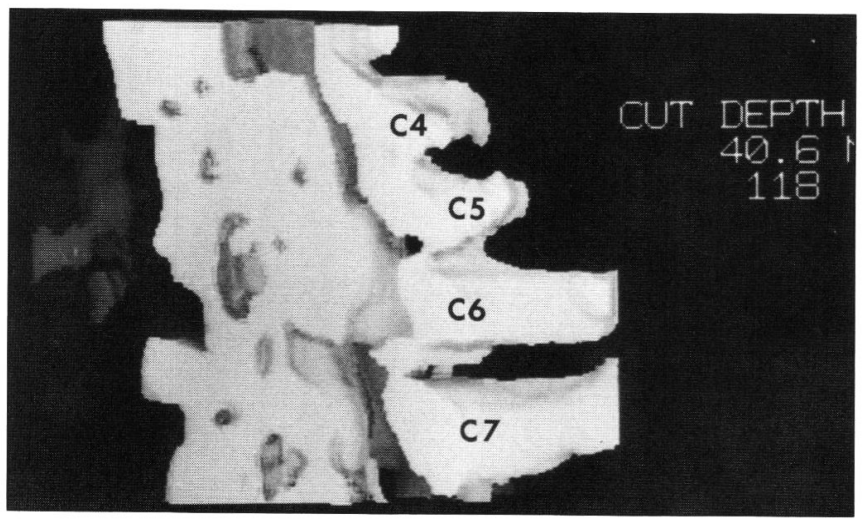

Figure 3 - Three dimensional CT. The intraspinal mass starts at CS and extends down to TI with irregular undulation in the posterior surface making the canal very narrow. The most significant encroachment is at the C6 level. around the bony mass, radiculopathy may persist or worsen..$^{2,14}$ Anteriorly locating compressive masses are removed at great risk by the posterior route. ${ }^{15.22 .23}$

On the other hand, the anterior approach has the major advantage of possible extirpation of the anterior compressing mass. Although the surgical procedure is lengthy and requires post operative fixation with Halo vest the results are generally favourable. Abe reported 12 cases treated with anterior decompression and fusion.' Remarkable or moderate improvement of both radicular and spinal cord signs was obtained in all 12 cases. Harsh followed 19 cases for a mean period time of 15 months after medial corpectomy and fusion, and found functional improvement in all of 17 patients with cervical myelopathy. ${ }^{2}$ Kojima applied this procedure to 45 patients with cervical myelopathy due to multi-level spondylosis in 19 patients, OPLL in 12 , and combined pathology in $14 .{ }^{24}$ He reported 39 of 45 patients $(87 \%)$ had good results and 5 patients $(11 \%)$ did not improve.

Decompressive laminoplasty is another procedure for those with extensive involvement of more than 3 or 4 levels, and those with a large plaque at $\mathrm{C} 2$ or $\mathrm{T} 1$ because the length of bone graft for anterior interbody fusion may be limited and medial corpectomy of $\mathrm{C} 2$ or $\mathrm{T} 1$ may be difficult. ${ }^{1.21,25.26}$ The procedure should be decided upon taking account for all those factors such as age, general condition, severity of symptoms and extension of the lesion.

Regardless of the procedure, it is crucial that surgeons understand the nature and extension of lesions precisely. From the experience of this case, three dimensional display of lesion was extremely informative.

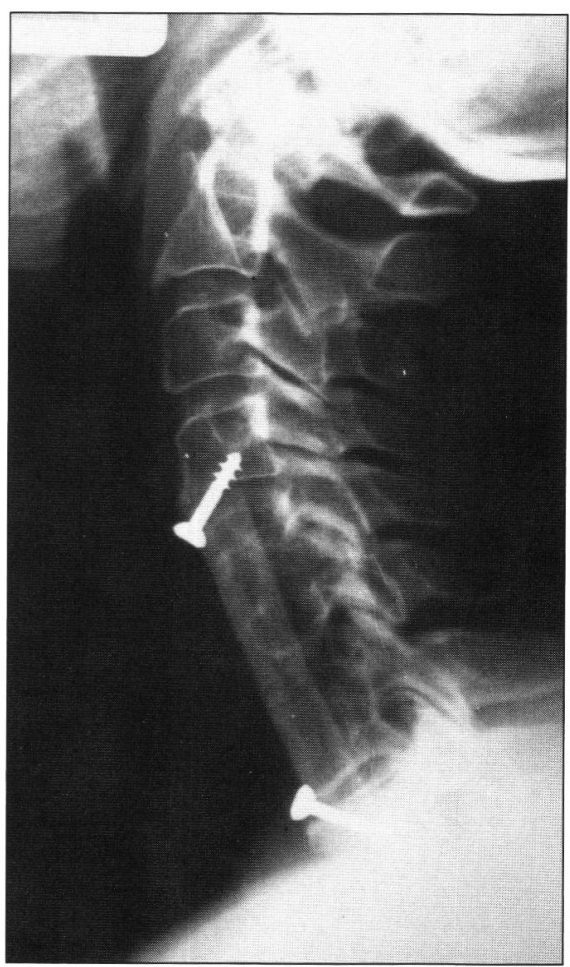

Figure 4 -Post-operative C. Spine X-ray. Free fibula graft with screw in place. 


\section{ACKNOWLEDGEMENT}

This paper was presented at the 21 st Annual Meeting of the Canadian Neurosurgical Congress in Halifax. The authors are grateful to Mrs. Sharon Wadden for secretarial work.

\section{REFERENCES}

I. Abe H, Tsuru M, Ito T, Iwasaki Y, Koiwa M. Anterior decompression for ossification of the posterior longitudinal ligament of the cervical spine. J Neurosurg 1981; 55: 108-116.

2. Harsh GR IV, Sypert GW, Weinstein PR, Ross DA, Wilson CB. Cervical spine stenosis secondary to ossification of the posterior longitudinal ligament. J Neurosurg 1987; 67: 349-357.

3. Terayama K, Maruyama S, Miyashita R, et al. [Ossification of the posterior longitudinal ligament in the cervical spine.] Orthop Surg 1965; 15: 1083-1095 (Jpn).

4. Hiramatsu Y, Nobechi T. Calcification of the posterior longitudinal ligament of the spine among Japanese. Radiology 1971; 100: 307-312.

5. Okamota Y, Yasuma T. Ossification of the posterior longitudinal ligament of cervical spine with and without myelopathy. J Jap Ortho Assoc 1967; 40: 1349-1360.

6. Singh A, Jolly SS, Bansal BC, Mathur CC. Endemic fluorosis. Epidemiological, clinical and biochemical study of chronic fluorine intoxication in Panjab (India). Medicine 1963; 42: 229-246.

7. Tezuki A, Yamada K, Ikata T, Kitagami Y, Yonezawa M. Ossification of the posterior longitudinal ligament of the cervical spine; its pathogenesis and treatment. Tokushima J Exp Med 1976; 23: 19-28.

8. Tsukimoto H. Autopsy case with spinal cord compression syndrome secondary to intra-spinal ossification. (In Japanese Case). J Jap Ortho Assoc 1960; 34: 107.

9. Yoshikawa S, Shiba M, Suzuki A. Spinal cord compression in untreated adult cases of vitamin D-resistant rickets. J Bone Joint Surg 1968; 50-A(4): 743-752.

10. Yamauchi $\mathrm{H}$. Roentgenographic investigation of the ossification of the cervical posterior longitudinal ligament in the United States of America. Orthop Surg (Jap) 1977; 28: 757-765.

11. Izawa $K$. Comparative roentgenographical study on the incidence of ossification of the posterior longitudinal ligament and other degenerative changes of the cervical spine among Japanese, Koreans, Americans and Germans. Nippon Seikeigeka Gakkai Zasshi 1980; 54: 461-469.
12. Lee T, Chacha PB, Orth MCh and Khoo J. Ossification of posterior longitudinal ligament of the cervical spine in non-Japanese Asians. Surg Neurol 1991; 35: 40-44.

13. Dong FC. Ossification of the posterior longitudinal ligament of cervical spine (in Chinese). Chung Hua Wai Ko Tsa Chih 1980; 18: 392-394.

14. Bakay L, Cares HL, Smith RJ. Ossification in the region of the posterior longitudinal ligament as a cause of cervical myelopathy. J Neurol Neurosurg Psychiatry 1970; 33: 263-268.

15. Briedal P. Ossification of the posterior longitudinal ligament in the cervical spine. "The Japanese disease" occurring in patients of British descent. Australas Radiol 1969; 13: 311-313.

16. Hyman TA, Merten JB, Stein HL. Computed tomography in ossification of the posterior longitudinal ligament. Neuroradiology 1977; 3: 227-228.

17. Minagi $\mathbf{H}$, Groner AT. Calcification of the posterior longitudinal ligament: a cause of cervical myelopathy. Am J Roentgnol 1969; 105(2): 365-369.

18. Palacios E, Brackett CE, Leary DJ. Ossification of the posterior longitudinal ligament associated with a herniated intervertebral disc. Radiology 1977; 100: 313-314.

19. Nagashima C. Cervical myelopathy due to ossification of the posterior longitudinal ligament. J Neurosurg 1971; 37: 636-660.

20. Philip DG. Surgical treatment of myelopathy with cervical spondylosis. J Neurol Neurosurg Psychiatry 1973; 36: 879-884.

21. Hanai K, Fujiyoshi F, Kamei K. Subtotal vertebrectomy and spinal fusion for cervical spondylotic myelopathy. Spine 1986; 11 : 310-315.

22. Adams CBT, Logue V. Studies in cervical spondylotic myelopathy. III. Some functional effect of operations for cervical spondylotic myelopathy. Brain 1971; 94: 587-594.

23. Bohlman HH. Cervical spondylosis with moderate to severe myelopathy. A report of seventeen cases treated by Robinson anterior cervical discectomy and fusion. Spine 1977; 2: 151-162.

24. Kojima T, Waga S, Kubo Y, et al. Anterior cervical vertebrectomy and interbody fusion for multi-level spondylosis and ossification of the posterior longitudinal ligament. Neurosurgery 1989; 24(6): 864-872.

25. Manabe S, Momura S. Anterior decompression for ossification of the posterior longitudinal ligament of the cervical spine. J Bone Joint Surg (Br) 1974; 56: 30-36.

26. Tomita K, Momura S, Umeda S, Baba H. Cervical laminoplasty to enlarge the spinal canal in multilevel ossification of the posterior longitudinal ligament with myelopathy. Arch Orthop Trauma Surg 1988; 107: 148-153. 